www.ccsenet.org/ijbm

\title{
The Optimal Supermarket Service
}

\author{
Yuejian Jie \\ College of Sciences, China Agricultural University, Beijing 100094, China \\ E-mail: jieyj@cau.edu.cn
}

\begin{abstract}
According to economic theory, this paper studies about waiting cost of every unit time and customer, on the condition of adding cost of a serviceman, on the scope of free time and time customer expending on system.
\end{abstract}

Keywords: Supermarket service, Waiting cost

\section{Introduction}

Under the condition of market economy, enterprises pursue for the maximum profits with fixed costs. Facing today's serious market competition, supermarket should not only satisfy customers' needs but also make best use of service sources. Along with the continuous development of market economy, more and more supermarkets appear in cities and towns. In fierce market competition, lots of supermarkets give priorities to the quality of commodities. They examine every chain carefully, first the product procurement, second the warehouse entry inspection, and third the quality of shelf products, excluding every unqualified products out of supermarkets. Secondly, supermarkets take the expansion of fields, the extension of scale, and the increase of sales as the key for survival and development. The first is to adjust commodity structure in time and enlarge business scope. The second is to explore business channels and promote chain business. With the precondition of insuring the quality of commodities and the base of optimizing commodity structure, how to improve enterprises' business effect and how to absorb more customers arouse more attentions from supermarkets. Check-out stands are the service windows of supermarkets, which not only reflect supermarkets' images but also associate with supermarkets' service quality and business efficiency. The standards for customers selecting supermarkets are not only qualified and inexpensive commodities but also service quality. The long queue waiting for check-out is not an ideal purchasing environment for people. Most people prefer to give up or go away instead of waiting in queue. With similar quality and price, service quality is the key for winning the competition. For supermarkets, more check-out stands mean more investments. Sometimes, it may cause waste of sources. However, few check-out stands may lead to serious waiting, affecting service quality, and causing loses of customers. This paper will probe into supermarkets' service management and optimization based on relevant queuing theory.

\section{Theoretical Model for Supermarket Service}

Supermarkets aim at self shopping. They pursue for quick returns and small margins. However, lots of supermarkets notice customers' needs and lay stresses on services. They understand that the overall service is the key for the success of supermarkets. Customers, service institutions, and queuing phenomenon are a queuing system. The basic model includes the input process, the service time, the service institution, and queuing rule. The supermarket service system is an $\mathrm{M} / \mathrm{M} / \mathrm{C}$ model (customer source, capacity are unlimited. And $\mathrm{C}$ service stands are connected together). The input process is a Poisson distribution. The service time is negative exponential distribution. The service institution means lots of service stands. The queuing rule is for service institution. The waiting system means customers have to wait if the service stand is in busy.

In a statistical balance state, the service intensity $\rho=\frac{\lambda}{c u}<1$.

Here the stability probability of this system is

(1) $P_{0}=\left[\sum_{n=0}^{c-1} \frac{1}{n !}\left(\frac{\lambda}{u}\right)^{n}+\frac{1}{c !}\left(\frac{\lambda}{u}\right)^{c} \frac{c u}{c u-\lambda}\right]^{-1}$ 
(2)The average length of queue $\quad L_{q}=\sum_{n=c+1}^{\infty}(n-c) P_{n}=\sum_{n=c+1}^{\infty}(n-c) \frac{c^{c}}{c !} \rho^{n} P_{0}$

$$
=\frac{c^{c}}{c !} P_{0} \rho^{c+1} \sum_{k=1}^{\infty} k \rho^{k-1}=\frac{(c \rho)^{C}}{c !(1-\rho)^{2}} \rho P_{0}
$$

(3) The average length of queue $L_{S}=L_{q}+c \rho$

(4) The average waiting time for customers in queue $W_{q}=\frac{L_{q}}{\lambda}$

(5) The average waiting time for customers in the system $W_{S}=\frac{L_{S}}{\lambda}=W_{q}+\frac{1}{u}$

(6) The waiting cost $C^{\prime}=\frac{2 u}{L_{q}}$

\section{Examples for Application}

$\lambda$ : Average arrival ratio of customers.

$u$ : Average service ratio.

In a supermarket survey in Beijing, in the $\lambda=18.5$ capita / hour and $u=9$ capita $/$ hour

$M / M / C$, establish the number of servers that makes customers' waiting time no more than $16 \%$ and each customer spends no more than $30 \mathrm{~min}$ in the system. If the cost for increasing every server for every unit time is 12 Yuan, then how the waiting cost for each customer per unit time determined by decision - making?

As $c=1$

$P_{0}=1-\rho=1-\frac{18.5}{9}=-0.85($ Imperfect $)$

As $c=2$

$$
\begin{aligned}
P_{0} & =\left(1+\frac{\lambda}{u}+\frac{1}{2 !}\left(\frac{\lambda}{u}\right)^{2} \frac{2 u}{2 u-\lambda}\right)^{-1} \\
& =\left(1+\frac{18.5}{10}+\frac{1}{2}\left(\frac{18.5}{10}\right)^{2} * \frac{2.10}{18.5}\right)^{-1} \\
& =(1+1.85+22.817)^{-1}=0.039<0.15
\end{aligned}
$$




$$
\begin{aligned}
W_{S}= & \frac{L_{S}}{\lambda}=W q+\frac{1}{u} \\
& =\frac{\rho}{\lambda(1-\rho)^{2}} \frac{(c \rho)^{C}}{c !} P_{0}+\frac{1}{u} \\
& =\frac{1.85}{18.5(1-1.85)^{2}} * \frac{(2 * 1.85)^{2}}{2 !} * 0.039+\frac{1}{10} \\
& =\frac{1.85}{1.85 * 0.723} * \frac{13.69}{2} * 0.039+\frac{1}{10} \\
& =0.369 \text { (hour })=22.15(\text { minute }) \prec 30 \text { minute }
\end{aligned}
$$

Therefore, the opminal number of servers is 2

Average waiting time: $W q=W s-\frac{1}{u}=0.369-0.1=0.269$ (hour) $=16.16$ (minute)

Average length of queue : $L q=\lambda W q=18.5 * 0.269=4.9765$

When hire 2 servers, the waiting cost for each customer per unit reaches the maximum

$$
C^{\prime}=\frac{2 U}{L q}=\frac{20}{4.9765}=4.019 \text { (Yuan) }
$$

Conclusion: based on introducing practical data into the model, we conclude that the waiting cost for each customer per unit time reaches the maximum 4.019 Yuan as hiring 2 servers. It is in accordance with facts. Therefore, this model is practical.

\section{Discussions on the Defects of the Model}

The supermarket service model is in accordance with facts in general. However, there are still some defects and problems hard to be solved.

Firstly, supermarket service is a flowing service system. In this paper, data are merely records during certain time period in one area. Supermarket service system has a strong liquidity. Customers may face kinds of choices. This issue can not be solved by this model.

Secondly, customers' choice for supermarkets is affected by personal income, geological location, and consumption preference. This model does not take these factors into consideration. It is not in accordance with facts and will affect the preciseness of the model.

\section{Suggestions and Countermeasures}

Chain supermarket, as a new business mode, brings about the second revolution of retail commerce due to its special sale mode "high turnover, low profits, competitive price and quality, self-service, and one- for-all purchase". This business mode greatly drives the circulation of commodities.

In recent more than one decade, various chain supermarkets have gained fast development in China. The competition tends to be more serious. Especially, after China' WTO entry, foreign large supermarkets enter China's retail market, forming a huge impact on China's retail industry. People realize that it is necessary to strengthen supermarket management and build special core competitiveness as reforming the selling mode.

This paper offers a model reflecting supermarket service optimization. This model is based on customers' requirements for shorter waiting time and supermarkets' needs for making best use of sources. To design an optimal waiting scheme can effectively improve supermarkets' service efficiency, which can improve customers' satisfaction and loyalty. Along with the fast development of economy, people cherish time more and more. Competition for supermarket service is fiercer. How to solve the conflict between customers and supermarkets deserves more considerations. Here, the author puts forward some opinions. Supermarkets managers should always take the management as the core for development. They can explore a set of management tools that are right for certain supermarket. Firstly, keep in perfecting supermarkets' management system. Set up relevant work rules for different positions. Make up safety protection system and perfect supermarket service management further. Organize employees to study relevant rules and learn from their suggestions. Form a set of scientific and preciseness system that is right for one supermarket. In the implementation of relevant rules, managers must sustain the strictness and the preciseness in practice. By this way, the management will be more regular. Secondly, set up strict performance assessment system for employees. Constitute leveled goalresponsibility system for every department. Responsibilities are for everyone. Form an assessment team and evaluate 
everyone's performance periodically. For the excellent performance, the management level should offer rewards. For the unqualified performance, the management can offer trainings. Strict performance assessment can greatly improve employees' responsibilities and motives in work. Thirdly, strengthen learning and training. Offer kinds of trainings periodically, especially in fields of marketing, customer psychology, and product quality. Organize managers and employees to learn from large supermarkets, concerning their advanced management methods and experiences. By means of observations and trainings, supermarkets can train a batch of talents and experts for relevant positions. The first-class management can create first-class service. The first-class service can create the first-class effects.

\section{References}

Cheng, Limin. (2002). Operations Research Model and Method. Beijing: Tsinghua University Press.

Hu, Yunquan. (1990). Basis and Applications of Operations Research. Harbin: Harbin Institute of Technology Press.

Luo, Ming'an. (1998). Operations Research. Beijing: Economic Management Press. 